\title{
A Review of Evaporation Reduction Methods from Water Surfaces
}

\author{
Yara Waheeb Youssef* and Anna Khodzinskaya \\ Moscow State University of Civil Engineering, Yaroslavskoe shosse, 26, Moscow, 129337, Russia
}

\begin{abstract}
Many methods have been tested and developed all over the world to save water from evaporation process. This paper presents a stateof-art review of published research work in the last 14 years (from 2014 to 2018) in which it was focused on the physical, chemical and biological methods of evaporation reduction from water surfaces. The main characteristics, as well as the advantages and disadvantages of each method are indicated. Among these used techniques for reducing evaporation are physical methods that use floating or suspended covers and can save a large percentage of water (between 70 and 95\%). The use of thermal mixing by compressed air seems to be very important for evaporation suppression on deep reservoirs (greater than $+18 \mathrm{~m}$ ). Moreover, currently chemicals are widely used to reduce water evaporation, such as WaterSavr, and can save relatively a small percentage of water (between $20-40 \%$ ). Biological methods such as floating plants, wind breakers and palm fronds can provide a significant decrease in the volume of evaporation but they have some restrictions on their uses.
\end{abstract}

\section{Introduction}

Although water covers more than $70 \%$ of the Earth, only $1 \%$ of the Earth's water is available for drinking. Moreover, population growth, pollution and global warming are placing never-before-seen pressure on the Earth's available water resources; therefore, the cost of water in many countries of the world with an arid or semi-arid climate has increased significantly over the past ten years. Evaporation is one of the most important environmental processes that can reduce the quality and quantity of water available for industrial, agricultural and household uses; therefore, evaporative losses become an essential challenge for the efficiency of water storage and supply and in many parts of the globe [1].

Efforts to reduce evaporation from water reservoirs started in the 1960s using monolayer molecular films as an impermeable barrier for the water surface. Since then, a lot of methods that provide a better control of the evaporation losses have been developed. Among these techniques, physical methods, such as floating covers or suspended covers atmosphere [2]. In addition, the use of thermal mixing by compressed air appears to have important potential for evaporation reduction on deep reservoirs [3]. As well as, biological

\footnotetext{
* Corresponding author: yarayoussef2811@ hotmail.com
} 
covers such as aquatic plants, wind breakers and palm fronds can reduce significantly the volume of evaporation from water reservoir [4].

The objective of this paper is to present the published results in the last 14 years (from 2004 to 2018) from field, laboratory, and numerical investigations of methods of evaporation reduction from water surfaces.

\section{Methods}

Published work in the last 14 years (from 2004 to 2018) on the physical, chemical and biological methods of evaporation reduction from water surfaces was assembled in this paper. The results of articles, conference papers, books and technical reports were gathered to present the main characteristics, advantages and disadvantages of each method.

\section{Results and discussion}

The following is a classification of physical, chemical and biological methods of evaporation reduction from water surfaces.

\subsection{Physical Methods of evaporation reduction that use floating covers}

Floating covers can be continuous covers (floating sheets) or modular covers (floating objects) [5].

\subsubsection{Floating continuous covers}

Floating continuous covers generally make an impermeable barrier that floats on the water surface to reduce evaporation. Polystyrene, wax and foam have been tested as used materials for making floating continuous overs, but polyethylene plastic has proved to be the most acceptable and durable material for covers of this type. Tests have shown that floating sheets such as E-VapCaps can reduce over 95\% evaporation from open water reservoirs [6].

\subsubsection{Floating modular covers}

As opposed to the continuous floating covers, the modular floating covers are individual units that can float freely and do not completely cover the water surface; therefore, they increase the transfer of dissolved oxygen DO through the open gaps formed between them. Aquacaps and shade balls are examples of the used floating modular covers.

Floating discs (aquacaps), as shown in Fig. 1, are round, dom-shaped floating modules of about $1.1 \mathrm{~m}$ in diameter and made up of polypropylene and high density polyethylene (HDPE), which both satisfy food grade standards. A single hole of about $10 \mathrm{~mm}$ in diameter is placed in the center of the aquacap to provide pressure equalization and to expel air when the cover is placed on the water $[5,7]$.

A study was carried out with a laboratory scale to estimate the efficiency of floating elements in reducing evaporative losses from water reservoirs. They used two small basins, covered and uncovered. The covered basin was a square-shaped water reservoir of $1.44 \mathrm{~m}^{2}$ area and $0.16 \mathrm{~m}$ depth while the floating discs were black and white colored Styrofoam discs of $0.2 \mathrm{~m}$ diameter and $0.02 \mathrm{~m}$ thickness that covered $91 \%$ of the water surface. The influence of wind and shortwave radiation on the evaporation rates from water surface was considered by using an upstream wind tunnel and four Xenon light sources. The results 
have shown that evaporation from the covered reservoir was reduced by about $80 \%$ relative to the uncovered water surface. However, changes in cover color did not significantly modify the evaporative rate. [8].

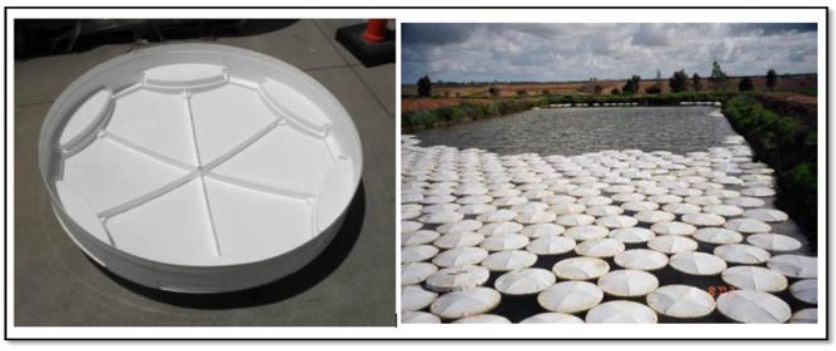

Fig. 1. Aquacaps.

Shade balls are plastic Eco-friendly balls that could be used in lakes, ponds stream and dams as shown in Fig. 2. The Department of Water and Power (LADWP) has first used these balls in California, Los Angels, in 2011 to prevent the evaporation and block UV rays leading to prevent the formation of harmful organisms, algae and carcinogens.

A study was conducted in the Nehru pond at Namakkal district, India to evaluate the efficiency of using of shade balls in reduction evaporation from water surface. They used 4inch black balls from high density polyethylene (HDPE) and carbon black to cover the reservoir. This study showed that the shade balls reduced $43-45 \%$ of evaporation in the reservoir [9]

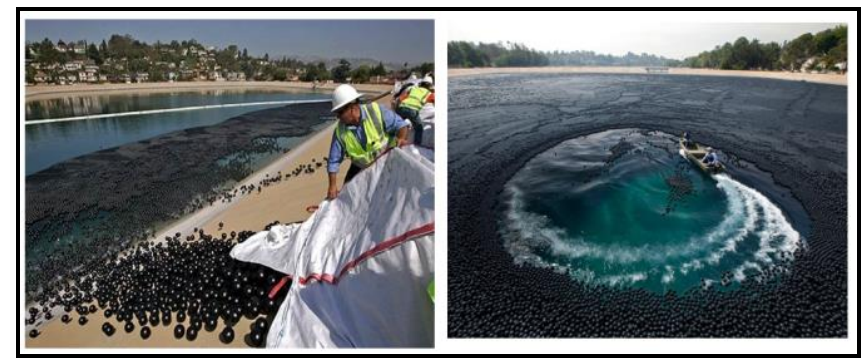

Fig. 2. Shade balls.

\subsection{Physical Methods of evaporation reduction that use suspended covers}

\subsubsection{Shadecloth}

Shadecloth are suspended structures installed over water surfaces with supporting poles and steel cables. This cover reduces the action of wind and blocks incoming solar radiation, therefore, it reduces the evaporation rates from water surfaces [5]. Shadecloth is economically used for small reservoirs that are less than 10 hectares in area. The main disadvantage of this method is the relatively high capital cost for construction but this has now been overridden in Malaysia owing to a new shadecloth knitting machine, which will produce wider rolls and, therefore, reduce the number of installed cables [6].

A study carried out under summer conditions in Southern Spain to estimate the efficiency of shading meshes in reducing evaporation from free water surfaces. They tested 2 Class-A pans, one uncovered and the other covered with different types of shading covers including single and double-layered polyethylene covers of different colours and a single 
layered aluminized cover. It was shown that shading covers led to decrease the evaporation by $50 \%$ for the aluminized cover and by about $80 \%$ for the coloured-polyethylene covers. In addition, the condensation over the black polyethylene covers reached up to $15-20 \%$ of the daily evaporation losses. This study has shown that there are some requirements that affect on choosing the material of the shadecloth, such as its colour, porosity and the capacity in improving the condensation during the night [2].

Another study was conducted in Australia to estimate the benefits of shadecloth covers for water reservoirs. They tested 6 water storages in different sites, 4 of them were covered using Commercial 95 shadecloth as shown in Fig. 3, and were observed for one year uncovered and one year covered, while the 2 remained storages were uncovered to act as control reservoirs and were observed for two years. The study has shown that evaporation rate was reduced by about $90 \%$ and the shadecloth reduced maintenance costs because they delay the growth of aquatic plants at the bottom of the storages. In addition, shadecloth led to improve water quality because they prevent the birds and other animals from entering the water storages. However, the problems with these covers are minor compared to their advantages [10].

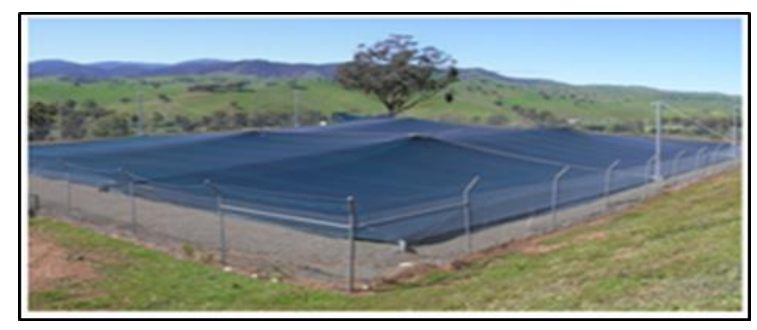

Fig. 3. Shadecloth cover above Swifts Creek Storage, Australia.

\subsubsection{The cover of solar photovoltaics PV}

Covering the canals with a solar photovoltaics system (SPVS) is expected to significantly reduce evaporation. However, Evaporation rates from flowing canals can take values as high as 5-20 mm/day. [11]. India has been a pioneer country in the field of canal-top solar projects. In February 2014 was inaugurated a $10 \mathrm{MWp}$ project of this kind in India with a total cost of $\$ 18.3$ billion. The system lays over $3.6 \mathrm{~km}$ of the Narmada irrigation canal in Gujarat's Vadodara city in western India, consists of 33,816 solar panels as shown in Fig. 4. Owing to using this system, 6 acres of land and about 9 million liters of water are saved every year. Natural cooling of SPVS is an additional advantage of using solar panels over irrigation canals, leading to increase the efficiency of the solar panels by $7 \%$, compared to ground SPVS [12].

A research analyzed the possibility of alternative choices for SPVS installations to be implemented on the downstream face of dams and over irrigation canals in the Mediterranean islands because they have limited water resources and a wealth of solar potential. 15 canals were selected: 11 in Sardinia (Italy), 3 in Sicily (Italy) and 1 in Cyprus. It was generally expected $3000 \mathrm{~m}^{3}$ of water savings per MWp of SPVS. This research concluded that the SPVS has the potential to secure $\approx 170,000 \mathrm{~m} 3$ of water from canals, annually. However, impoving the aesthetics of the regions around the canals is an additional advantage for using of SPVS over canals [11]. 


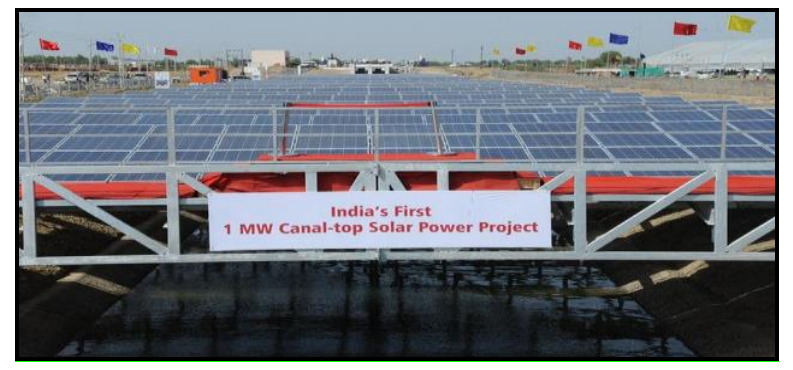

Fig. 4. Solar panels above the Narmanda irrigation canal, India.

\subsection{Physical Method of evaporation reduction by injection of air bubbles into water (bubble plume)}

The principle of this method is shown in Fig. 5. In summer, the surface water of a reservoir, which is called epilimnion, heats and becomes less dense. Below this surface layer, which is 3 to $4 \mathrm{~m}$ deep and called hypolimnion, the water remains cold and denser. These layers are separated by a thermocline that acts as a barrier to normal convection circulation and prevents the hypolimnetic water from being mixed with the epilimnion water. This phenomenon is commonly called stratification. Artificial destratification will happen when injecting a bubble plume in the cold deep layer. Consequently, the evaporation is reduced by uniforming temperature gradients over the depth of the storage. Diffusers, which inject bubble plumes, are placed at a specific height above the bottom of the reservoir to prevent the disruption of the bed sediments and carrying them to the surface [3].

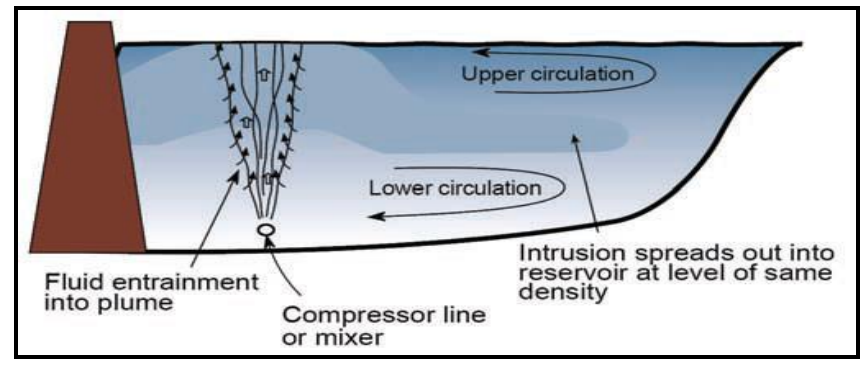

Fig. 5. Typical circulation pattern set-up by artificial destratification.

Gordon E. Koberg and Maurice E. Ford were the first researchers who suggested using bubble plumes to reduce evaporation from reservoirs. They studied the effects of bubble aeration on the temperature and evaporation from Lake Wohlford, California, USA in 1962. The lake Wohlford has a volume of $3.1 \mathrm{Mm}^{3}$, an area of 53.1 ha and a maximum depth of only $15 \mathrm{~m}$. An air bubble plume system was remained operating continuously for over a period of 3 months. Temperatures were observed and compared with measured temperature from 3 previous years (1959-1961) when no aeration was used. Evaporation rate was indirectly estimated by the energy budget method using the measured temperatures. The study has shown that compared with the previous three years, during 1962 the surface temperatures were lower, as well as the evaporation was reduced by $15 \%$ during summer (from May to June) and increased by $9 \%$ during winter (from September to November). These differences were justified by the operation of the aeration system in 1962. It was concluded that these systems could lead to an annual water saving of $6 \%[3,13]$.

Further research on evaporation reduction by air-bubble plumes was conducted in South Africa. Two small artificial reservoirs A and B (Reservoir A as the benchmark) were 
constructed in Pretoria-West. Thermocouple sensors were placed in Reservoir B at levels of $150,250,350,450$ and $1150 \mathrm{~mm}$ below the surface and an electronically controlled air regulator was used to create the bubble plume in Reservoir B. The results showed for a 2month period (May and June) an evaporation reduction in Reservoir B of about 1\% per month compared with Reservoir A, and that was because of the small depth of the reservoirs, which did not allow for the development of accentuated thermal stratification.

Another experiment was also conducted at Roodeplaat Dam, which is a concrete arch dam of $55 \mathrm{~m}$ in height situated in South Africa. The purpose of this study was to obtain an optimum system that would have the greatest effect on the water surface temperatures. A HDPE pipe of $20 \mathrm{~mm}$ in diameter and $200 \mathrm{~m}$ in length was laid under the water into the dam and a diffuser was placed at a depth of about $16 \mathrm{~m}$. Various layouts were used to modify the volume and the shape of the bubble plume as well as the release times and intervals. As shown in Fig. 6 a bubble plume was released every 10 min with recording happens at $2 \mathrm{~min}$ intervals. The surface water temperature obviously drops by 1 to $2.5^{\circ} \mathrm{C}$ when a bubble plume is released. The main conclusion drawn by the authors was that, for the effective use of bubble plume system in reducing evaporation, the reservoir should have a sufficient depth (more than $+18 \mathrm{~m}$ ) to produce a marked natural thermocline and provide a relatively large volume of cold water for mixing to reduce the surface temperature. It was also found that the proposed system could have additional benefits, such as improving water quality, reducing operating costs for water treatment, increasing the levels of dissolved oxygen (DO) in water, increasing the fish habitat and algal growth reduction. However, on the other negative side, there are some water users who require the temperature of the abstracted water for potable use to be within a certain range and below a specific maximum. Moreover, some fish species habitats in the thermocline layer could be destroyed when the lake is destratified [3].

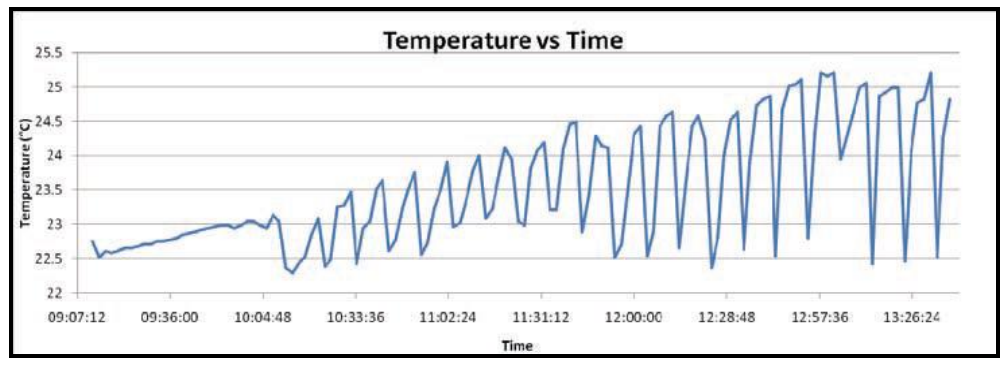

Fig. 6. Example of surface water layer temperature changes.

\subsection{Chemical methods of evaporation reduction}

Chemical mono-layers are single molecular layers ( 2 millionths of a mm thick) of insoluble or sparingly soluble compounds. When applied to water these compounds form an invisible film that can be used to cover a reservoir and block evaporation. Chemical monolayers reduce evaporation by creating an insoluble film of a single layer of packed fatty alcohol molecules that acts as a physical barrier to water molecules escaping the surface (pores smaller than $\mathrm{H}_{2} \mathrm{O}$ ) and a possible shield from air movements interacting with water surface molecules. In addition, the polar charged hydrophobic and hydrophyllic molecular ends reduce the surface tension of water thus lowering the surface area available for evaporation [1].

Chemical mono-layers for evaporation reduction have been in research and development since the 1920s. Hexadecanol and octadecanol combinations were found to form the most effective barrier for preventing water molecules from evaporating $[1,14]$. 
The first field experiment was carried out in Australia in the beginning of the 50's, and the obtained evaporation reductions of $30 \%$ called attention of many research groups and governments around the world $[15,4]$.

Now chemicals are widely used to reduce water evaporation such as WaterSavr, which is a commercially available product used successfully in Australia, the United States and other countries. It is an odourless white powder that automatically and quickly spreads into an invisible, molecule-thin film over the surface of water. It is an internationally patented blend of calcium hydroxide (hydrated Lime $\mathrm{Ca}\left(\mathrm{OH}_{2}\right)$ ), food grade stearyl alcohol $\left(\mathrm{C}_{18} \mathrm{H}_{37} \mathrm{OH}\right.$, commonly referred to as octadecanol) and cetyl alcohol $\left(\mathrm{C}_{16} \mathrm{H}_{33} \mathrm{OH}\right.$, commonly referred to as hexadecanol) that can reduce surface water evaporation by $20-50 \%$ without negative environmental impacts.

The self-spreading mechanism is a natural chemical reaction that results from the "ionic repulsion" of the positively charged $\mathrm{Ca}^{+}$calcium ions disassociated when calcium hydroxide is applied to the water. As the hydrated lime (represented in yellow) starts to dissolve in the water, the resulting positively charged calcium ions repel each other and spread across the water's surface, carrying the hydroxy alkanes (represented in purple) along with the lime particle (Figure 7). The ionic forces are strong enough to overcome waves and up to $16 \mathrm{~km} / \mathrm{hr}$ winds helping push WaterSavr into all corners of a reservoir. It is fully biodegradable within about 48- 72 hours.

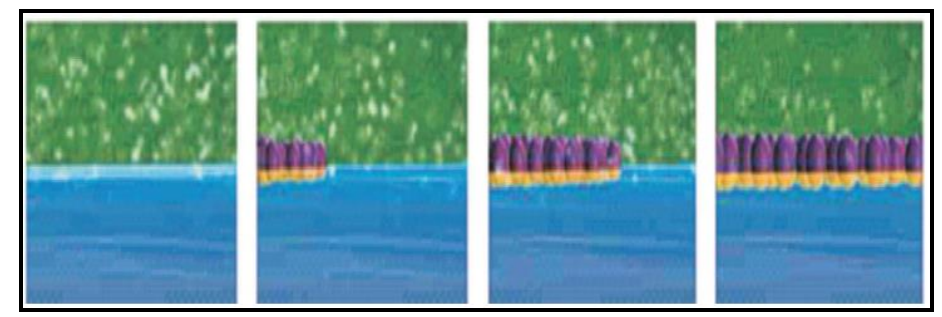

Fig. 7. Self-spreading mechanism of WaterSavr.

A research was conducted to evaluate the efficiency of WaterSavr in evaporative reduction under tropical conditions at the Bedok reservoir in Singapore. The reservoir has a surface area of 84 hectares, a capacity of 12.8 million $\mathrm{m}^{3}$, mean depth of about $9 \mathrm{~m}$, a maximum depth of $18.2 \mathrm{~m}$ and shoreline length of about $4.3 \mathrm{~km}$. To test the real life impacts of WaterSavr on Bedok Reservoir, four M60R automated WaterSavr applicators produced by Global Equipment Services of Australia were anchored on the reservoir. Each spreader has a capacity of 50-60 kg and was deployed to cover about 20 hectares. The units can be set to dose the reservoir with WaterSavr automatically at any time by using a solar panel, battery and timer as shown in Fig. 8. The main conclusion drawn by the authors was that, WaterSavr saved $30 \%$ of water lost due to evaporation. In addition, WaterSavr can become a very cost-effective method in maximizing Singapore's water supply and it does not show any negative impacts to public health, the environment or water quality [1]. 


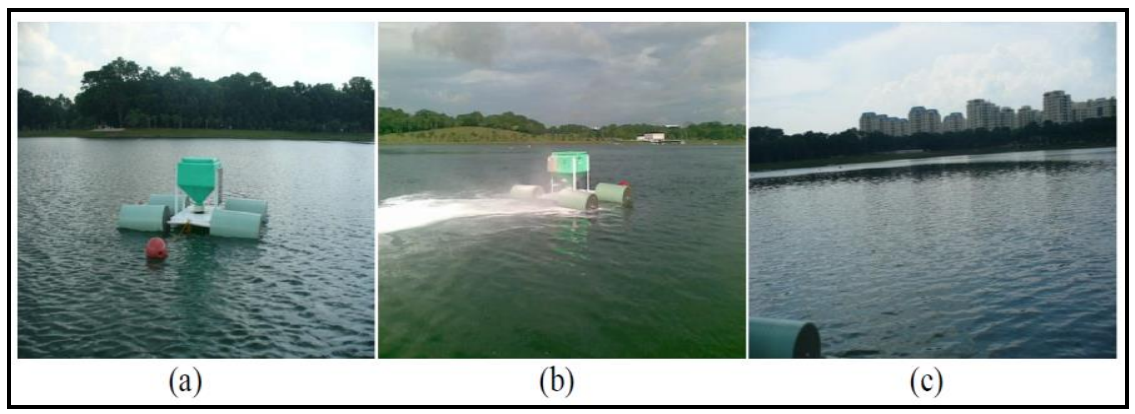

Fig. 8. (a) Anchored Spreaders; (b) Automatic dosing of WaterSavr on the Reservoir; (c) WaterSavr (mono-layer) spreading

Another study was carried out to evaluate the efficiency of alcohols monolayers to reduce the water evaporation from open water reservoirs in southern Algeria. 3 Colorado partially-buried evaporation pans were filled by water by $80 \%$ of total volume. The first pan was covered with octadecanol monolayer, the second with mixture of hexadecanol and octadecanol monolayer $(1: 1)$ and the third was the control one, which contained only water. These compounds were put on the water surface as a powder every three days. The study has shown that the monolayers rised water temperature but they could reduce evaporation rate, which depends on the material used to form these monolayers. However, using of mixture of hexadecanol and octadecanol has achieved the best evaporation reduction rate (24\%). In addition, it was shown that the air temperature and wind speed affect monolayers' performance in reducing evaporation [16].

\subsection{Method of biological covers}

\subsection{1 floating plants}

Floating aquatic plants such as water lily, small duckweed, great duckweed and water meal can reduce the evaporation of water reservoirs by preventing the connection between air and the boundary layer of water. Studies in Thailand have shown that duckweed can reduce evaporation up to $10 \%$. However, not all water plants effectively reduce evaporation rates. For instant, water lotus and water hyacinth have wide extended leaves that increase the transportation surface area and evaporation rates. Moreover, some aquatic plants can affect water quality and the nature flora dynamics, therefore, research on the efficiency of using aquatic plants must be conducted before using them in a water storage. [14].

Palm fronds, which are usually available in arid regions, can be used to cover water surfaces. A study tested the efficiency of palm fronds in reducing evaporation from three pools that were constructed in Riyadh at King Saud University. It was found that the average reduction in evaporation using a floating cover made up of palm leaves was $55 \%$ for the fully covered pool while it was only $26 \%$ for the half covered pool [17]. Another study carried out using covers made of palm fronds in Riyadh at King Saud University. The used evaporation pan was of $1210 \mathrm{~mm}$ internal diameter, $250 \mathrm{~mm}$ deep and made up of $1 \mathrm{~mm}$ thick galvanized steel sheet. It was found that using of a single-layered cover can reduce up to $47 \%$ in evaporation, while using a double-layered cover leads to a reduction in evaporation rate by $58 \%$ [18]. Moreover, the studies recommended to use palm fronds for open water surfaces to reduce evaporation because they have no harmful effects on water quality and withstand hot weather conditions of the arid areas $[17,18]$. 


\subsubsection{Wind breakers}

Wind is one of the most important factors that affect the rate of evaporation from water surfaces. Planting of trees normal to the direction of windward is an effective method for reducing of evaporation losses.

A numerical and field investigation, which was conducted in semi-arid western Australia, showed that earthen banks can reduce evaporation by $6 \%$. In addition, for $\mathrm{X}_{\mathrm{w}} / \mathrm{H}=$ 15 (where $\mathrm{X}_{\mathrm{w}}$ is the waterbody length, $\mathrm{H}$ is the height of the barrier) construction of a windbreaks, which have a porosity of $30 \%$, on the earthen bank, increased the shelter effect and reduced evaporation by about 15-25\%. Reservoirs located downwind with large natural shelterbelts $\left(\mathrm{X}_{\mathrm{w}} / \mathrm{H}<7.5\right)$ seemed to have noticeable evaporation reductions of about $28 \%$ compared with the reservoirs without any shelters [19].

Another study, which was carried out on the Wivenhoe Dam in Queensland, Australia, showed that the wind breaks, which consist of tree "shelterbelts", reduce the wind speed by $80 \%$ for a distance of $5 \mathrm{~m}$ times the height of the tree $(\mathrm{H})$. The results also showed that the annual reductions in evaporation of 2.5, 3.6 and 5.6\% can be achieved for 20,30 and $40 \mathrm{~m}$ high windbreaks respectively. These percentages were estimated to be even smaller, at 1.1, 2.0 and $3.8 \%$ at $60 \%$ of the full supply. However, wind breakers are effective only for small sized reservoirs and not useful in large reservoirs [4].

\section{Conclusion and recommendations}

The following conclusions were made from this study:

1. Physical methods of evaporation reduction can save a large percentage of water (between 70 and 95\%), their capital costs are high, but their maintenance costs are not expensive.

2. Chemical methods of evaporation reduction save a small percentage of water (between $20-40 \%$ ), their capital costs are not large, but their maintenance costs are significant.

3 . The influence of surface area should be more noticeable for chemical methods, since under the action of the waves, the films are destroyed, and the influence of the wind depends on the acceleration length. In addition, the temperature of the water affects the destruction of the film.

4. The method of injection of air bubbles into the water is the most effective method of reducing evaporation in deep water bodies (for depth greater than $+18 \mathrm{~m}$ ).

5. Biological covers can provide a significant decrease in the volume of evaporation. However, the water drawn up and used for transpiration by plants needs to be taken into account to estimate the efficiency of using them for the pupose of evaporation reduction .

6 . Reducing the exposed area of water surface, building deeper reservoirs and storing water in underground storage should be considered in water storages design, because these design features are long term methods for reducing the evaporation.

\section{References}

1. P. Babu, H. S. Eikaas, A. Price, D. Verlee, Reduction of Evaporative Losses from Tropical Reservoirs using an Environmentally Safe Organic Monolayer, proceeding of Conference of Singapore International Water Week, at Singapore, (2010)

2. V. Martı'nez Alvarez, A. Baille, J.M. Molina Martı'nez, M.M. Gonza'lez-Real, J. Agric. Water Manag. 84, 229-239 (2006)

3. M v. Dijk, SJ v. Vuuren, AJOL 35, 2 (2009) 
4. F. Helfer, H. Zhang, C. Lemckert, Evaporation Reduction by Windbreaks: Overview, Modelling and Efficiency, Urban Water Security Research Alliance, technical report No. 16 (2009)

5. X. Yao, H. Zhang, C. Lemckert, A. Brook, P. Schouten, Evaporation Reduction by Suspended and Floating Covers: Overview, Modelling and Efficiency, Technical Report No. 28 (2010)

6. I.P. Craig, Loss of storage water due to evaporation - a literature review. NCEA publication, University of Southern Queensland, Australia (2005)

7. H. Baldwin, Assessment of Floating Hard Covers on Large Water Storages, Urban Water Security Research Alliance, technical report No. 27, (2010)

8. M. Aminzadeh, P. Lehmann, and D. Or, J. Hydrol. Earth Syst. Sci. 22, 4015-4032 (2018)

9. P.Vasantha Kumar, S.V.Naveen Kumar, P.Saravana Kumar, S.Subash, M.Sivaraja, IJET 4,2 (2018)

10. K. Hunter, N. Finn, S. Barnes, The benefits of shadecloth covers for potable water storages, proceeding of 70th Annual Water Industry Engineers and Operators' Conference Bendigo Exhibition Centre, ( 2007)

11. I. Kougias, K. Bódis, A. Jäger-Waldau, M. Moner-Girona, F. Monforti-Ferrario, J. Sol. Ener. (SEJ) 136, 174-182 (2016)

12. A. Keya, Solar Plant A top Irrigation Canal Impresses UN Chief. India Climate Dialogue, (2015)

13. F. Helfer, Influence of Air-Bubble Plumes and Effects of Climate Change on Reservoir Evaporation, PhD Thesis, Griffith University, Australia, pages 7-8 (2012)

14. E. Elba, Strategies for protection and sustainable environmental management or the Highest Aswan dam in Egypt considering climate change, disserta verlag, Hamburg, page 36 (2017)

15. M. Gugliotti, M. S. Baptista, M. J. Politi, J. Braz. Chem. Soc. 16, 16A (2005)

16. S. saggai, D. Boutoutaou and O. E. Bachi, IJETAE 5, 1 (2015)

17. S. A. Al-Hassoun, T. A. Mohammed, J. Nurdin, JEAS 4, 247-250 (2009)

18. S. Alam, A. A. AlShaikh, J. King Saud University, Engineering Sciences (JKSUES) 25, 55-58 (2009)

19. M.R. Hipsey, M. Sivapalan, T.P. Clement, J. Environ. Fluid Mech 4, 79-106 (2004) 